\title{
Desenvolvimento morfológico dos ovários em embriões e fetos bovinos da raça Nelore
}

\author{
[Morphological development of the ovaries in embryos and fetuses of Nelore breed] \\ E.G. Diniz ${ }^{1}$, C.R. Esper ${ }^{2}$, J.O. Jacomini ${ }^{1}$, R.C. Vieira ${ }^{1}$ \\ ${ }^{1}$ Faculdade de Medicina Veterinária da Universidade Federal de Uberlândia \\ Av. Pará 1720 \\ 38408-283 - Uberlândia, MG \\ ${ }^{2}$ Universidade do Estado de São Paulo - UNESP - Jaboticabal, SP
}

\begin{abstract}
RESUMO
Investigaram-se os eventos morfológicos relacionados ao desenvolvimento pré-natal de ovários de 81 embriões e fetos da raça Nelore, coletados em frigoríficos, com idades variando de 26 a 240 dias pósfecundação. Observou-se formação da crista gonádica e presença de células germinativas em seu interior aos 29 e 34 dias, respectivamente. As oogônias e folículos primordiais, ao contrário dos folículos em crescimento, apresentaram diferenças significativas de diâmetro nos vários períodos estudados. Verificouse correlação positiva $(\mathrm{P}<0,05)$ entre o diâmetro das oogônias e de seus núcleos, bem como entre o diâmetro dos folículos primordiais e em crescimento com seus oócitos e respectivos núcleos. A gônada apresentou-se completamente formada aos 40 dias. Folículos primordiais, em crescimento e antrais surgiram, aproximadamente, aos 95, 140 e 180 dias, respectivamente. Na raça Nelore, a oogênese tem início e duração semelhante à de raças taurinas, mas apresenta como peculiaridade a antecipação do surgimento da foliculogênese.
\end{abstract}

Palavras-chave: bovino, Nelore, diferenciação sexual, ovário, célula germinativa

\begin{abstract}
The morphologic events related to the prenatal development of the ovaries in 81 Nelore breed embryos and fetuses gathered in a local slaughterhouse, with age range from 26 to 240 days following fecundation were studied. The age of fetuses was estimated from measures taken in the cranium-caudal direction. The sex was identified from macroscopic observations and using Polymerase Chain Reaction (PCR) technique. For histology the gonads were fixed in Bouin's fluid for 24 hours and 5 um thick section's were stained with hematoxylin-eosin. Formation of gonadal ridge and presence of germinal cells were found within it at 29 and 34 days, respectively. Oogonia and primordial follicles, unlike the growing follicles, exhibited significant differences in diameter in the various periods studied. Positive correlation $(P<0.05)$ was found between the diameter of oogonia and their nucleus as well as between primordial and growing follicles with their oocytes and respective nuclei. The gonad was fully formed at 40 days. Primordial follicles, in the growing stage, and antral follicles first appeared, approximately at 95, 140, and 180 days, respectively. Despite the onset and duration of oogenesis being similar to that of taurine breeds, folliculogenesis initiates at an early stages in the Nelore breed.
\end{abstract}

Keywords: sexual differentiation, ovary, germ cell, bovine

Recebido para publicação em 26 de setembro de 2003

Recebido para publicação, após modificações, em 5 de abril de 2004

E-mail: egdiniz@umuarama.ufu.br 


\section{INTRODUÇÃO}

Estudos sobre o desenvolvimento pré-natal das gônadas em bovinos foram feitos, na sua maioria, em animais de raças européias, sendo escassos os trabalhos sobre o assunto envolvendo as raças zebus.

A crista gonádica revela-se como a primeira manifestação do desenvolvimento das gônadas de mamíferos, constituindo-se num relevo da parte medial dos túbulos mesonéfricos (Fujimoto et al. 1977; Mackay, 2000). As células germinativas primordiais (CGP), por sua vez, não se formam do material inicial do esboço da gônada, mas se originam à distância e posteriormente migram para esta em todas as espécies de mamíferos (Mclaren, 2000). De acordo com Peters (1970), as CGP surgem extragonadalmente no saco vitelino e migram via endoderma do intestino posterior até 0 mesentério, daí para as pregas mesonéfricas e, finalmente, atingem a crista gonádica. Uma vez neste local, proliferam intensamente entre 5 e 6 semanas, tornam-se hiperplásicas e assumem aspecto amebóide, espalhando-se entre o epitélio celômico e o mesênquima. Já no interior da gônada em formação, as CGP iniciam sua diferenciação em oogônias e se dividem rapidamente por mitose.

Existe um consenso de que na maioria dos mamíferos o processo de oogênese é completado antes ou logo após o nascimento, quando as oogônias entram em prófase da meiose, tornamse por definição oócitos e cessam a atividade mitótica. Em investigações com embriões e fetos bovinos, Erickson (1966) constatou que a meiose iniciava-se nos fetos decorridos 75 a 80 dias póscoito. Por seu turno, a mitose cessava entre 150 e 180 dias, com a maioria dos oócitos atingindo sua fase de dictióteno, em paquíteno da prófase meiótica, sendo envolvidos nos folículos primordiais aos 170 dias. Em geral, oócitos circundados por uma única camada de células foliculares planas são denominados folículos primordiais. De acordo com Gropp e Ohno (1966), nos bovinos eles são formados nas regiões mais profundas da zona cortical em ovários de fetos apresentando 110 a $130 \mathrm{~mm}$ de comprimento. Foi bem estabelecido em diversas espécies de mamíferos que oócitos e folículos primordiais, após formados, têm seu número consideravelmente reduzido, mormente a partir da segunda metade da gestação (Motta e Makabe, 1986). Essa perda contínua seria conseqüência dos mecanismos de atresia folicular (Peters, 1970; Packer et al.,1998; Mclaren, 2000), apoptose ou esfoliação celular na superfície da gônada (Motta e Makabe, 1986).

O objetivo deste estudo foi caracterizar o desenvolvimento pré-natal da gônada feminina em embriões e fetos bovinos da raça Nelore, bem como quantificar, medir o diâmetro e conhecer aspectos morfológicos do desenvolvimento gonádico tais como: início da formação do ovário, surgimento de CGP, oogônias, oócitos e folículos nos diversos estádios de desenvolvimento.

\section{MATERIAL E MÉTODOS}

Foram coletadas as gônadas de 12 embriões e 69 fetos de vacas Nelore, abatidas em frigoríficos no município de Uberlândia, MG. À época da coleta procurou-se certificar se os fetos apresentavam características da raça Nelore e confirmar se as vacas tinham sido acasaladas com touros da mesma raça.

O sexo dos fetos foi determinado por observação macroscópica da genitália externa, enquanto que o dos embriões foi confirmado por meio da técnica de reação em cadeia de polimerase (PCR), conforme descrito por Kirkpatrick e Monson (1993).

A idade dos embriões e fetos foi estimada baseando-se na fórmula $\mathrm{DG}=8,4+0,087 \mathrm{C}+5,46 \sqrt{\mathrm{C}}$, em que $\mathrm{DG}=$ dias de gestação e $\mathrm{C}=$ comprimento do embrião ou feto, proposta por Rexroad et al. (1974). Eles foram mensurados imediatamente após retirados do útero.

As gônadas dos fetos ou dos embriões in totum foram fixadas em líquido de Bouin por 24 horas para estudos em microscopia ótica. As gônadas então fixadas foram medidas no comprimento, altura e largura visando estabelecer o seu volume. Seguiu-se a retirada de um fragmento e seu processamento em técnica histológica clássica, que consistiu em desidratação com álcool, diafanização em xilol e inclusão em parafina. Foram feitos cortes na espessura de $5 \mu \mathrm{m}$, dos quais pelo menos cinco seções diferentes foram coradas com hematoxilina e eosina. A montagem foi feita colocando-se uma 
gota de Bálsamo do Canadá sobre o corte e cobertura com uma lamínula, comprimindo-a de modo a espalhar o líquido numa fina camada entre lâmina e lamínula. Finalmente, os cortes histológicos corados foram analisados com microscópio de luz Olympus BX 4.0, equipado com câmera Oly 200 acoplada a microcomputador Pentium III. As imagens foram capturadas com objetivas de 10x e 40x.

A quantificação e determinação do diâmetro das células germinativas foram feitas por meio do software HLimage em microcomputador Pentium III, $450 \mathrm{Mhz}$ e monitor Samsung Sincmaster 450 b. A contagem das células foi feita por área do ovário, e seu número foi multiplicado pela espessura do corte $(5 \mu \mathrm{m})$ para se obter valores em $\mu \mathrm{m}^{3}$, que foram transformados em $\mathrm{mm}^{3}$ e, finalmente, multiplicados pelo volume da gônada. Uma vez que a espessura do corte foi menor que o diâmetro das estruturas medidas, e para evitar duplicidade na contagem em cada seção, seu diâmetro foi dividido pela espessura do corte, cujo valor encontrado serviu como divisor do número total de estruturas do ovário. Como resultado, obteve-se o número final de estruturas da gônada. O volume do ovário foi calculado com base na fórmula do elipsóide, por ser a figura geométrica que mais se aproxima de sua forma, ou seja, volume $=4 / 3 \pi a b c$, em que $a=$ comprimento $/ 2, b=$ largura $/ 2$ e $c=$ altura $/ 2$. A partir de aproximadamente 85 dias pósfecundação deduziu-se a área correspondente à região da medula, pelo fato dela estar definida e apresentar estruturas germinativas (oogônias e folículos) em quantidades mínimas, não participando, portanto, como área de cálculo.

Neste trabalho, folículos primários e folículos secundários foram denominados folículos em crescimento. Para os vários tipos de estruturas (oogônias, folículos primordiais e folículos em crescimento) foram estimados os coeficientes de correlação de Pearson entre as variáveis diâmetro da oogônia, do seu núcleo, dos oócitos e do núcleo destes. As comparações entre médias foram feitas pelo teste de Tukey a $5 \%$ de probabilidade pelo método general linear models (GLM) do pacote estatístico SAS (Procedures..., 1990). Utilizou-se o coeficiente de variação para comparar a variabilidade entre o número de células das várias estruturas porque elas foram colhidas de diferentes fetos e não continham o mesmo número de observações.

\section{RESULTADOS E DISCUSSÃO}

A crista gonádica foi observada inicialmente em embriões medindo de 12 a $15 \mathrm{~mm}$ de comprimento, entre 29 e 31 dias de idade (Fig. 1), confirmando observações feitas por Shim e Anderson (1998) e Wrobel e Süb (1998), tanto em fetos de bovinos, quanto em outros mamíferos. Noden e Lahunta (1990) relataram o aparecimento da crista gonádica em várias espécies de mamíferos em embriões de 9 a $10 \mathrm{~mm}$ ( \pm 27 dias $)$. Com a expansão da crista gonádica, CGP surgiram no seu interior em embriões de $20 \mathrm{~mm}$ ( \pm 34 dias), confirmando os estudos de Shim e Anderson (1998), quando afirmaram que, em períodos correspondentes, as CGP podiam ser identificadas por suas características morfológicas nas várias espécies de mamíferos. Nessa fase foram contadas 1331 CGP, número que aumentou para $6455 \mathrm{em}$ embriões de 25 a $30 \mathrm{~mm}$ ( \pm 40 dias), quando a gônada já se apresentava totalmente formada, resultado semelhante aos encontrados por Fujimoto et al. (1985), Godin et al. (1990) e Wrobel e Süb (1998). O diâmetro médio das CGP nessa fase foi de $8,15 \mu \mathrm{m}$, com o núcleo medindo $5,58 \mu \mathrm{m}$.

As oogônias foram encontradas em fetos de 48 a $50 \mathrm{~mm}$ ( \pm 50 dias) nas zonas mais profundas do ovário e não houve, nesse período, distinção entre as zonas cortical e medular. Nessa fase da oogênese houve expressivo aumento de oogônias, o que confirma os resultados de Peters (1970) e Moustafa e Hafez (1971). Foram contadas 130.471 células. O diâmetro médio das oogônias e o de seus núcleos são apresentados na Tab. 1. Em fetos de $70 \mathrm{~mm}$ ( \pm 60 dias), as oogônias aumentam em número e diâmetro e começam a agrupar-se em ninhos, fato também observado por Gondos et al. (1971), ao relatarem que a posterior fragmentação dos ninhos ou aglomerados celulares originavam os folículos primordiais. Em fetos de 140 a $150 \mathrm{~mm}( \pm 85$ dias) foram observados oócitos em divisão meiótica contornados por células foliculares iniciando a formação de folículos primordiais. Em fetos com mais de $200 \mathrm{~mm}$ (>100 dias) verificou-se diminuição drástica no número de oogônias, o que também foi relatado por Erickson (1966), em bovinos, e por Fujimoto et al. (1977), em humanos. 

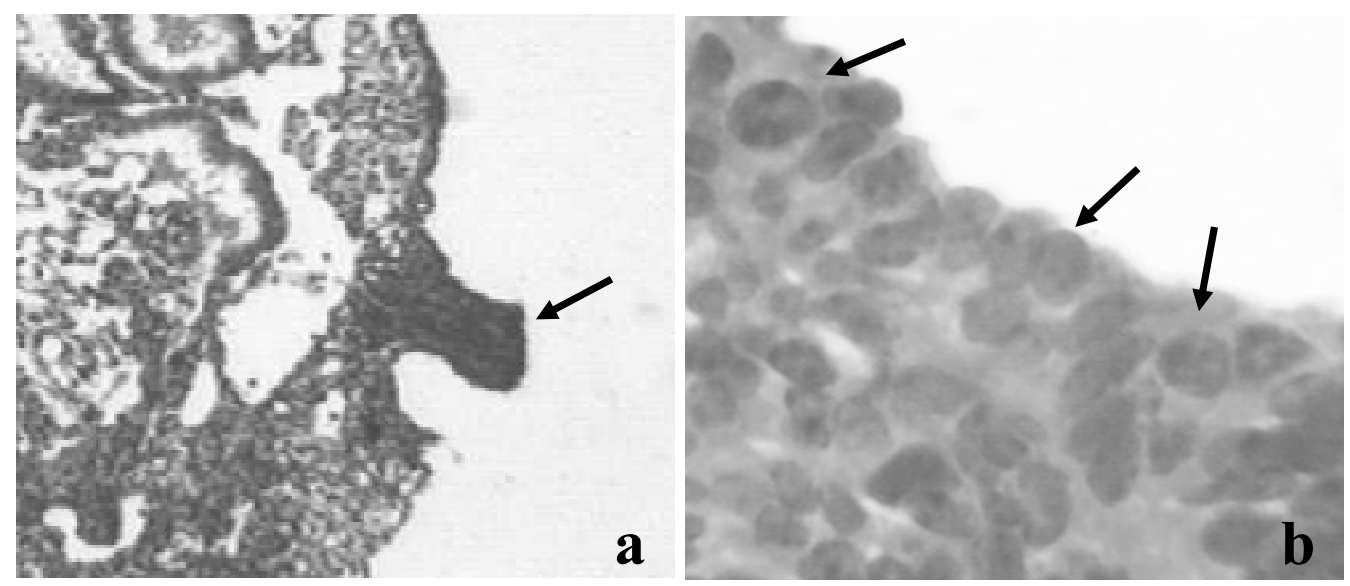

Figura 1. a: crista gonádica em embrião da raça Nelore medindo $20 \mathrm{~mm}$ ( \pm 34 dias de gestação). HE, 40X. b: crista gonádica com células germinativas primordiais (setas). HE, 400X.

Tabela 1. Média e desvios-padrão do diâmetro das oogônias e dos seus núcleos em fetos bovinos da raça Nelore nos vários períodos após a fecundação

\begin{tabular}{cccc} 
Dias após & Número de & \multicolumn{2}{c}{ Diâmetro $(\mu \mathrm{m})$} \\
\cline { 3 - 4 } a fecundação & células & Oogônia & Núcleo \\
\hline 50 & 45 & $10,66(0,63) \mathrm{d}$ & $6,63(0,49) \mathrm{d}$ \\
60 & 45 & $12,22(0,73) \mathrm{c}$ & $7,98(0,58) \mathrm{c}$ \\
100 & 45 & $14,73(1,07) \mathrm{b}$ & $9,19(0,87) \mathrm{b}$ \\
140 & 40 & $17,32(1,28) \mathrm{a}$ & $9,98(0,80) \mathrm{a}$ \\
\hline
\end{tabular}

Médias com letras distintas na mesma coluna diferem entre si pelo teste Tukey $(\mathrm{P}<0,05)$.

Observou-se correlação positiva entre o diâmetro das oogônias e o dos seus respectivos núcleos em todo o período estudado (Tab. 1). Observaram-se diferenças entre períodos quanto aos diâmetros das oogônias e dos núcleos. Estes resultados assemelham-se aos de Mackay (2000) e Mclaren (2000), ao afirmarem que as oogônias, à semelhança dos folículos antrais, apresentam contínuo aumento de diâmetro, até serem totalmente transformadas em oócitos ou serem consumidas por atresia ou apoptose.

Folículos primordiais foram observados inicialmente em fetos de $140 \mathrm{~mm}$ ( \pm 85 dias) como apresentado na Fig. 2a. Em fetos de $170 \mathrm{~mm}$ ( \pm 94 dias) eles estavam totalmente formados e localizados, principalmente, nas regiões mais profundas do córtex ovariano. Em fetos de $190 \mathrm{~mm}$ ( \pm 100 dias) foram encontrados 93.806 folículos primordiais com diâmetro médio de $35,6 \mu \mathrm{m}$, oócitos com $18,9 \mu \mathrm{m}$ e núcleos com $10,8 \mu \mathrm{m}$.

O diâmetro médio dos folículos primordiais, dos seus oócitos e dos respectivos núcleos também apresentaram correlação positiva e altamente significativa entre si (Tab. 2). Foram observadas diferenças $(\mathrm{P}<0,05)$ quando se compararam os diâmetros aos 100 dias com aqueles aos $140 \mathrm{e}$ 180 dias, mas não houve diferenças nos diâmetros entre 100 dias e diâmetros aos $210 \mathrm{e}$ 240. Isso indica que o diâmetro dos folículos primordiais com seus oócitos e núcleos tenderam a aumentar a partir de 100 dias pós-fecundação, mas diminuíram próximo ao final da gestação ( \pm 240 dias), quando se aproximaram dos valores encontrados aos 100 dias. A provável causa dessa redução de diâmetro deve-se ao fato de que aos 240 dias os folículos primordiais restantes provavelmente serão aqueles em estádio dictióteno e que permanecerão no ovário após o nascimento, compondo a população de folículos primordiais da fêmea até a puberdade, como sugerido por Noden e Lahunta (1990). 


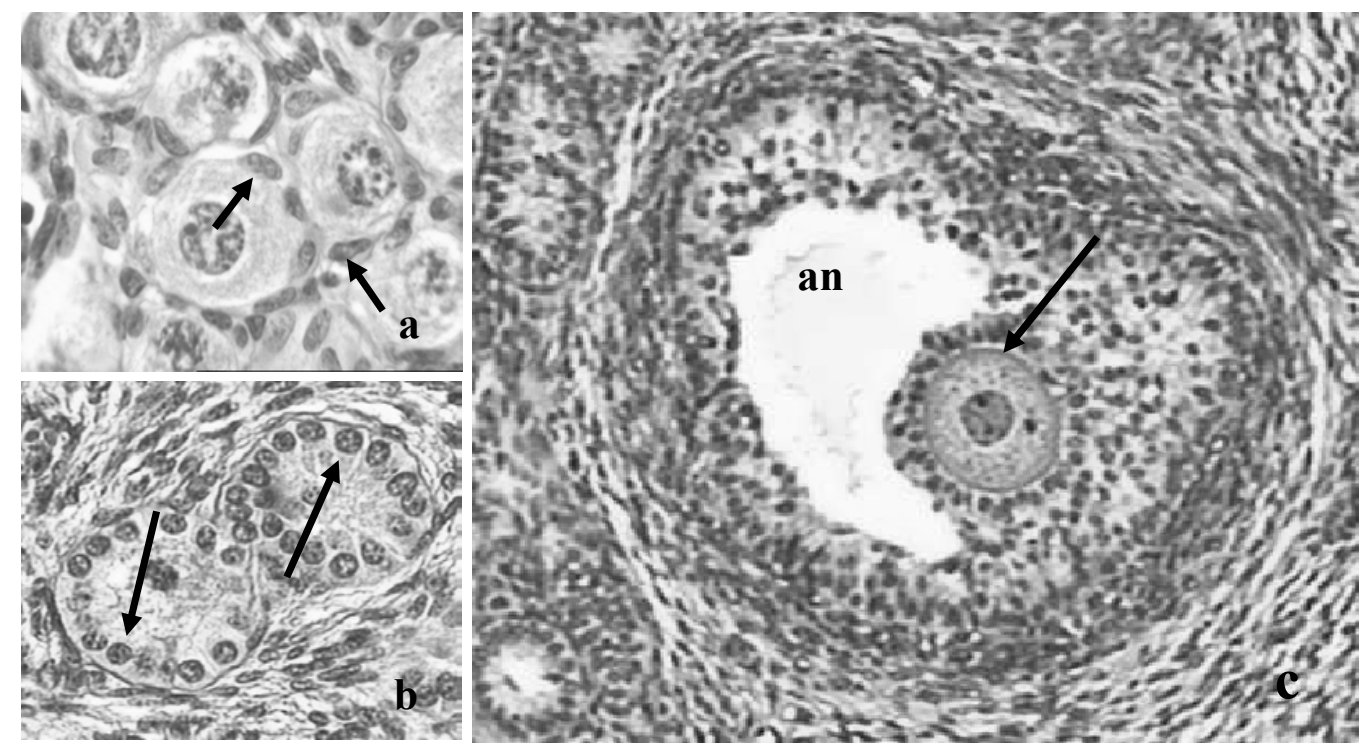

Figura 2. a: oócitos circundados por células foliculares planas (setas) em feto da raça Nelore medindo 260mm ( \pm 119 dias de gestação). HE, 400X. b: folículos primários com única camada de células cúbicas (setas) em ovário de feto da raça Nelore medindo 590 mm ( \pm 192 dias de gestação). HE, 400X. c: antro formado (an) e oócito circundado por nítida zona pelúcida (seta) em feto da raça Nelore medindo 590mm ( \pm 192 dias de gestação). HE, 400X.

Tabela 2. Média e desvios-padrão do diâmetro dos folículos primordias, dos seus oócitos e dos núcleos de fetos bovinos da raça Nelore nos vários períodos após a fecundação

\begin{tabular}{ccccc}
\hline \multirow{2}{*}{$\begin{array}{c}\text { Dias após } \\
\text { a fecundação }\end{array}$} & Número & \multicolumn{3}{c}{ Diâmetro $(\mu \mathrm{m})$} \\
\cline { 3 - 5 } de células & 44 & Folículo & Oócito & Núcleo \\
\hline 100 & 45 & $35,63(6,64) \mathrm{b}$ & $18,95(3,49) \mathrm{b}$ & $10,87(1,60) \mathrm{c}$ \\
140 & 30 & $39,64(3,61) \mathrm{a}$ & $23,37(3,34) \mathrm{a}$ & $12,82(2,16) \mathrm{a}$ \\
180 & 30 & $35,42(7,15) \mathrm{a}$ & $24,03(6,14) \mathrm{a}$ & $13,65(2,21) \mathrm{a}$ \\
210 & 31 & $35,38(2,26) \mathrm{b}$ & $20,05(0,96) \mathrm{b}$ & $12,68(0,96) \mathrm{ab}$ \\
& 340 & $19,37(1,60) \mathrm{b}$ & $11,55(1,20) \mathrm{ac}$ \\
\hline
\end{tabular}

Médias com letras distintas na mesma coluna diferem entre si pelo teste Tukey $(\mathrm{P}<0,05)$.

Folículos que apresentaram maior diâmetro (entre 140 e 180 dias pós-fecundação) atingiram fases mais adiantadas de desenvolvimento para, então, desaparecerem durante a fase final da gestação, como demonstrado em bovinos europeus por Erickson (1966), Peters (1970) e Moustafa e Hafez (1971). Entretanto, Mbassa (1989) relatou que em fetos zebuínos os folículos primordiais são formados a partir de 60 dias póscoito.

Os folículos primordiais aumentaram em número e diâmetro até aproximadamente 180 dias, com alguns apresentando células planas e cúbicas, fato indicativo de ativação folicular. No último terço da gestação, ou em fetos a partir de $700 \mathrm{~mm}$ ( \pm 210 dias), observou-se diminuição no número e diâmetro dos folículos, os quais foram encontrados exclusivamente na periferia da zona cortical, o que também foi observado por Peters (1970). As médias do diâmetro dos folículos primordiais, dos seus oócitos e dos respectivos núcleos são apresentadas na Tab. 2.

Em fetos de $350 \mathrm{~mm}$ ( \pm 140 dias $)$ foram contados 63.339 células que apresentaram diâmetro de $46,2 \mu \mathrm{m}, 26,6 \mu \mathrm{m}$ e $14,2 \mu \mathrm{m}$ para folículo, oócito e núcleo, respectivamente. 
O número de folículos em crescimento aumentou em fetos de 520 a $530 \mathrm{~mm}( \pm 180$ dias $)$ atingindo 163.216 células, surgindo, nessa fase, os primeiros sinais de formação da zona pelúcida. Em fetos de $700 \mathrm{~mm}( \pm 210$ dias $)$ eles continuaram a aumentar, ao contrário do que ocorreu com os folículos primordiais, e alcançaram 247.696 células. Em fetos de 750 a $800 \mathrm{~mm}$ ( \pm 240 dias) diminuíram em número para 81.135 células. Entre 210 e 240 dias os folículos em crescimento foram encontrados também na camada intermediária do córtex ovariano, diferindo dos relatos de Erickson (1966) e Peters (1970).
Observou-se correlação positiva $(\mathrm{P}<0,01)$ entre os diâmetros dos folículos em crescimento (Tab. 3), dos seus oócitos e dos respectivos núcleos, mas não ocorreram variações nos períodos estudados. Entre períodos, não houve diferenças significativas no diâmetro dos folículos. Houve diferença apenas no diâmetro dos oócitos dos folículos em crescimento $(\mathrm{P}<0,05)$, entre $140 \mathrm{e}$ 210 dias. Essas observações confirmam as encontradas por Peters (1970) em várias espécies de mamíferos. Provavelmente, isso ocorreu porque os folículos contendo oócitos de 210 dias já estariam em processo de atresia ou degeneração, enquanto que os acima de 210 teriam evoluído para folículos antrais ou teriam entrado em atresia somente após o nascimento.

Tabela 3. Médias e desvio-padrão do diâmetro dos folículos em crescimento, dos seus oócitos e dos núcleos de fetos bovinos da raça Nelore nos vários períodos após a fecundação

\begin{tabular}{ccccc}
\hline Dias após & Número & \multicolumn{3}{c}{ Diâmetro $(\mu \mathrm{m})$} \\
\cline { 3 - 5 } a fecundação & de células & Folículo & Oócito & Núcleo \\
\hline 140 & 44 & $46,22(4,59) \mathrm{a}$ & $26,60(2,71) \mathrm{a}$ & $14,19(1,51) \mathrm{a}$ \\
180 & 30 & $45,37(4,67) \mathrm{a}$ & $25,90(2,69) \mathrm{a}$ & $13,72(0,98) \mathrm{a}$ \\
210 & 28 & $45,35(4,90) \mathrm{a}$ & $24,84(2,62) \mathrm{b}$ & $13,80(1,01) \mathrm{a}$ \\
240 & 31 & $45,71(5,04) \mathrm{a}$ & $26,55(2,75) \mathrm{ab}$ & $13,83(0,90) \mathrm{a}$ \\
\hline
\end{tabular}

Médias com letras distintas na mesma coluna diferem entre si pelo teste Tukey $(\mathrm{P}<0,05)$.

O aumento no diâmetro da oogônia sempre foi acompanhado de aumento de diâmetro do seu núcleo em todos os períodos estudados (Tab. 1). Mackay (2000) verificou resultados semelhantes. Esse fato também aconteceu com o desenvolvimento folicular, que foi acompanhado pelo desenvolvimento do oócito e seu núcleo, até este atingir o estádio de dictióteno (Tab. 2 e Tab. 3).

Folículos secundários com evidências de formação de antro e folículos com antro totalmente formado (folículos terciários) foram incluídos na categoria de folículos antrais. Os primeiros folículos antrais foram encontrados nas zonas mais profundas do córtex ovariano em fetos de $530 \mathrm{~mm}$ ( \pm 180 dias $)$, diferindo das observações de Erickson (1966) e Jost e Prepin (1972), que indicaram o aparecimento deles a partir de 250 dias e 200 dias, respectivamente. Nessa fase, alguns folículos apresentaram zona pelúcida e antro em formação, enquanto outros zona pelúcida totalmente formada e oócitos circundados por células do cumulus oophorus (Fig. 2c). Nesse período foram encontrados
25.328 folículos. Em fetos de $750 \mathrm{~mm}( \pm 240$ dias) foram encontrados 3.071 folículos antrais.

Conclui-se que a formação do ovário em embriões e fetos da raça Nelore ocorreu em períodos semelhantes aos de bovinos europeus. Entretanto, apesar de a oogênese ter início e duração semelhantes, a raça Nelore, diferentemente das raças taurinas, tem como característica a antecipação do surgimento da foliculogênese.

\section{REFERÊNCIAS BIBLIOGRÁFICAS}

ERICKSON, B.H. Development and radioresponse of the prenatal bovine ovary. $J$. Reprod. Fertil., v.10, 97-105, 1966.

FUJIMOTO, T.; YOSHINAGA, K.; KONO, I. Distributions of fibronectin and the migratory pathway of primordial germ cell in mice. Anat. Rec., v.121, p.271-278, 1985.

FUJIMOTO, T.; YUKIHIRO, M.; MASATOSHI, F. The origin, migration and fine 
morphology of human primordial germ cells. Anat. Rec., v.188, p.315-330, 1977.

GODIN, I.; WYRLIE, C.; HEASMAN, J. Genital ridges exert long range effects on mouse primordial germ cell numbers and direction of migration in culture. Development, v.108, p.357361, 1990.

GONDOS, B.; BHURALEUS, P.; HABEL, C.J. Ultrastructure observations on germ cells in human fetal ovaries. Am. J. Obstet. Ginecol., v.110, p.644-652, 1971.

GROPP, A.; OHNO, S. The presence of a common embryonic blastema for ovarian and testicular parenchymal (follicular, interstitial and tubular) cells in cattle Bos taurus. Z. Zellforsch. Mikrosk. Anat., v.74, p.505-528, 1966.

JOST, A.; PRÉPIN, J. Données sur la migration des cellules germinales primordiales du foetus de veau. Arch. Anat. Microsc. Morphol. Exp., v.55, p.161-186, 1972.

KIRKPATRICK, B.W.; MONSON, R.L. Sensitive sex determination assay applicable to bovine embryos derived from IVM and IVF. $J$. Reprod. Fertil., v.98, p.335-340, 1993.

MACKAY, S. Gonadal development im mammals at the cellular and molecular levels. Int. Rev. Cytol., v.200, p.47-99, 2000.

MBASSA, G.K. Studies on the ovarian development in Zebu Cattle (Bos indicus). Anat. Histol. Embr., v.18, p.143-149, 1989.

McLAREN, A. Germ and somatic cell lineages in fine developing gonad. Mol. Cell. Endocrinol., v.163, p.3-9, 2000.
MOTTA, P.M.; MAKABE, S. Germ cells in the ovarian surface during fetal development in humans. A three dimensional microanatomical study by scanning and transmission electron microscopy. J. Submicrosc. Cytol. Pathol., v.81, p.271-276, 1986.

MOUSTAFA, L.A.S.; HAFEZ, E.S.E. Prenatal development of the bovine reproductive sistem. J. Reprod. Med., v.7, p.99-113, 1971.

NODEN, D.M.; LAHUNTA, A. Embriologia de los animales domesticos. Zaragoza: Acribia, 1990. 399p.

PACKER, C.; TATAR, M.; COLlinS, A. Reproductive cessation in female mammals. Nature, v. 392, p. 807-811, 1998.

PETERS, H. Migration of gonocytes in to mammalian gonad and their differentiation. Philos. Trans. R. Soc. London B, v.259, p.91101, 1970.

PROCEDURES guide. Version 6.0, 3.ed. Cary, NC: SAS Institute, 1990.

REXROAD, C.E.; CASIDA, L.E.; TYLER, W.J.M. Crown-rump length of fetuses in purebred Holstein-Friesian cows. J. Dairy Sci., v.57, p.346-347, 1974.

SHIM, H.; ANDERSON, G.B. In vitro survival and proliferation of porcine primordial germ cells . Theriogenology, v.49, p.521-528, 1998.

WROBEL, K.H.; SÜB, F. Identification and temporospatial distribution of bovine primordial germ cells prior to gonadal sexual differentiation. Anat. Embriol., v.197, p.451-467, 1998. 